University of Massachusetts Amherst

ScholarWorks@UMass Amherst

Chemistry Department Faculty Publication Series

Chemistry

1991

\title{
Continuous Flow Dilution for Flame Atomic Absorption Spectrometry Using a Variable Volume Dilution Chamber and Peak Area Measurement
}

\author{
Ernest Beinrohr \\ Slovak Technical University in Bratislava \\ Pavol Csemi \\ Slovak Technical University in Bratislava \\ Julian Tyson \\ University of Massachusetts Amherst
}

Follow this and additional works at: https://scholarworks.umass.edu/chem_faculty_pubs

Part of the Chemistry Commons

\section{Recommended Citation}

Beinrohr, Ernest; Csemi, Pavol; and Tyson, Julian, "Continuous Flow Dilution for Flame Atomic Absorption Spectrometry Using a Variable Volume Dilution Chamber and Peak Area Measurement" (1991). Journal of Analytical Atomic Spectrometry. 1385.

Retrieved from https://scholarworks.umass.edu/chem_faculty_pubs/1385 


\title{
Continuous Flow Dilution for Flame Atomic Absorption Spectrometry Using a Variable Volume Dilution Chamber and Peak Area Measurement
}

\author{
Ernest Beinrohr and Pavol Csémi \\ Department of Analytical Chemistry, Slovak Technical University, Radlinského 9, CS-812 37 Bratislava, \\ Czechoslovakia \\ Julian F. Tyson \\ Department of Chemistry, Lederle Graduate Research Tower A, University of Massachusetts, Amherst, MA \\ 01003, USA
}

\begin{abstract}
A simple procedure, based on flow injection, to extend the dynamic range of flame atomic absorption spectrometry (FAAS) has been investigated. The continuous dilution system consists of a sample injector for sample volumes of $15-1000 \mu \mathrm{l}$ and a variable volume $(0.1-10 \mathrm{ml})$ dilution chamber. Peak area measurement of the transient signal allowed the use of a simple standard solution for calibration and quantification. The linear dynamic range of FAAS can be enhanced by $2-3$ orders of magnitude; for copper a concentration range of from about 0.1 to $9 \times 10^{3} \mu \mathrm{g} \mathrm{ml}-1$ is achieved. The reproducibility of the measurements is $2-4 \%$.
\end{abstract}

Keywords: Flow injection; continuous flow dilution; variable volume dilution chamber; flame atomic absorption spectrometry; extension of linear dynamic range

Flame atomic absorption spectrometry (FAAS) is frequently used in analytical laboratories because of the simplicity of use, high selectivity and reliability. However the problems encountered with FAAS can be classified as follows: (i) spectral, physical and chemical interferences due to background absorbance, line coincidence, viscosity changes, ionization phenomena, stable compound formation, etc:; (ii) it is a singleelement method; (iii) the sensitivity is unsatisfactory for ultratrace analysis; (iv) significant volumes of sample are consumed in the most frequently used continuous aspiration mode; and (v) narrow linear response range.

The last point is of great importance when samples with high or widely differing analyte concentrations are being analysed. Various methods can be used to extend the useful concentration range, for example; choice of a less sensitive wavelength, utilization of the non-linear calibration region, decreasing the optical pathway by adjusting the burner slot and dilution of the sample solution. However, all of these methods require re-calibration after adjusting the experimental conditions, which is laborious and time consuming.

An alternative method is to use flow systems which incorporate dilution manifolds ${ }^{1-4}$ which improve the dynamic range of FAAS significantly, by altering the dispersion within the system. Variation of the dispersion can also be achieved by controlled timing of a specific operation, e.g., the sample aspiration. The peak width may be used as a quantitative parameter enabling a significant enhancement in the concentration range of the elements being determined. ${ }^{6.7}$

The present paper describes the theoretical and experimental basis of continuous flow dilution in a variable volume mixing chamber and calibration through peak area measurement, which enables simple quantification of the contents of samples with analyte concentrations covering a broad range. The utility of the method was verified experimentally by analysing solutions of copper.

\section{Theoretical}

A block diagram of the continuous flow calibration device and flame atomic absorption spectrometer is illustrated in Fig. 1. The sample of volume $V_{0}$ with a concentration $c_{0}$ is injected into the carrier liquid flowing at a rate of $u$ (i.e., aspiration rate). The sample plug enters the mixer chamber, of volume $V_{\mathrm{M}}$. Considering a well stirred tank model, the concentration

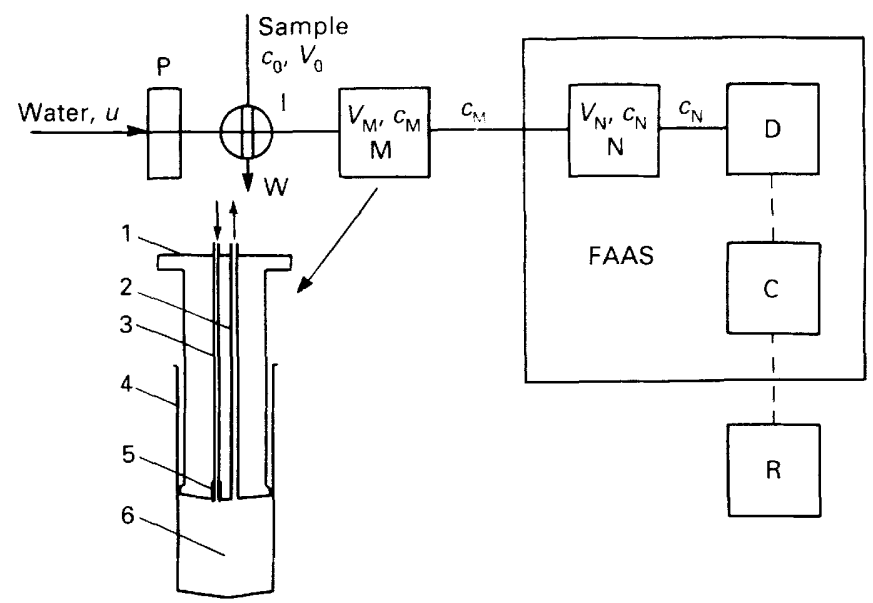

Fig. 1 Block diagram of the continuous flow dilution system. P, Peristaltic pump; I, injection port; W, waste: M, mixing (dilution) chamber; $N$, nebulizer; D, detector; C. microcomputer; and R, chart recorder. For other abbreviations see Table 1. Dilution chamber (insert): 1, piston; 2, outlet; 3 , inlet: 4 , valve; 5 , glass capillary linked to the inlet tubing; and 6 . inner space

inside the chamber $\left(c_{M}\right)$ equals the output concentration. This sample output enters the nebulizer, which can be regarded as a well stirred single tank with a hypothetical volume of $V_{\mathrm{N}}{ }^{x .4}$ The concentration of the sample flow output reaching the detector is $c_{\mathrm{N}}$.

The detector response, related to transmittance $(T)$, is usually converted into absorbance by an analogue or digital procedure.

The measured absorbance $(A)$ at time $t$, in the linear response range is directly proportional to the concentration $c_{\mathrm{N}}$ :

$$
A_{t}=k c_{\mathrm{v}}
$$

where $k$ is the sensitivity. The time dependence of concentration $c_{N}$ and that of the absorbance can be expressed mathematically by considering a theoretical model of two tanks in series in a manner similar to that described for models for a single tank $^{8.9}$ or two tanks in parallel.10

The maximum absorbance $\left(A_{\mathrm{m}}\right)$ (peak height) can be obtained by differentiating the absorbance-time function as follows:

$$
A_{\mathrm{m}}=k c_{10} \alpha
$$


where

$$
\left.\alpha=\left[\exp \left(V_{0} / V_{\mathrm{N}}\right)-1\right]^{V_{\mathrm{N}} /\left(V_{\mathrm{N}^{-}} V_{\mathrm{M}}\right)}\left[\exp \left(V_{0} / V_{\mathrm{M}}\right)-1\right)\right]^{\left.V_{\mathrm{M}^{\prime}} / V_{\mathrm{M}^{-}} V_{\mathrm{N}}\right)}
$$

As equation (2) implies, peak height is determined by the sample volume and concentration by the volume of the mixing chamber and the hypothetical volume of the nebulizer. It does not depend on the flow-rate unless the sensitivity changes at the same time.

The dispersion $(D)$ of the sample in this system can be expressed by the following equation:

$$
D=A_{0} / A_{\mathrm{m}}=1 / \alpha
$$

where $A_{0}=k c_{0}$.

The peak area $(a)$ at time $t\left(a_{t}\right)$ can be derived by integrating the absorbance values in the time interval from $t=0$ to $t$. The limiting value of the peak area $(t \rightarrow \infty)$ can be expressed mathematically either by integrating the absorbance-time function ${ }^{\prime \prime}$ or by making use of the mass balance of the system. Both approaches, unless the absorbance is outside the linear response range, lead to the same relationship, namely

$$
a=k c_{0} V_{0} / u
$$

Unlike peak height, peak area is dependent on the flow-rate.

Thus, the analyte concentration can be expressed simply as a linear function of the ratio $a / V_{0}$. The useful concentration range is then limited at the lower end by the minimum and from above by the maximum of the ratio $a / V_{0}$.

In spectrometric measurements where digital signal processing is used, peak area can be calculated directly from the actual transmittance values:

$$
a=\sum_{i=1}^{N} \Delta t A_{i}=-\Delta t \sum_{i=1}^{N} \log T_{i}=-\Delta t \log \prod_{i=1}^{N} T_{i}
$$

Where $N$ is the number of digital readings. The peak area can be obtained by multiplying one transmittance value by the next, and so on over the course of the measurements. In this way transformation of the primary spectrometric signal (transmittance) into absorbance can be omitted.

The derived equations imply the following features for the use of the continuous dilution system and peak area measurement of the signal: $(i)$ the concentration of the original injected sample solution can be determined simply from the ratio of peak area to sample volume [equation (4)]; (ii) since the ratio $a / V_{0}$ can access useful values over a much broader range than just using absorbance values the analyte concentrations can also cover a correspondingly broader interval; (iii) the extent of the sample dilution should be controlled by proper choice of the dispersion [equation (3)] to ensure that the absorbance maximum is in the linear response range of the instrument.

Calibration can be performed by measuring the steady-state signal in the system depicted in Fig. 1. Standard solutions with analyte concentrations in the linear response range were used instead of the water carrier. The coefficient $k$ is calculated using equation (1). An alternative method of calibration is to inject known volumes of standard solutions into the continuous dilution system and on integrating the signal the coefficient $k$ is calculated from equation (4). Both calibration methods should produce the same results if the instrumental parameters are kept constant.

\section{Experimental}

The measurements were performed on a double-beam atomic absorption spectrometer AAS 3 (Carl Zeiss Jena, Germany) with an air-acetylene flame. The instrumental parameters used were those recommended by the manufacturer: wavelength $324.8 \mathrm{~nm}(\mathrm{Cu})$ and $285.2 \mathrm{~nm}(\mathrm{Mg})$, slit-width $0.40 \mathrm{~mm}(\mathrm{Cu})$ and $0.20 \mathrm{~mm}(\mathrm{Mg})$.
The flow injection system is illustrated schematically in Fig. 1. The various parts of the system were connected with $1 \mathrm{~mm}$ i.d. PTFE tubing. Sample volumes of from $15 \mu$ to $500-1000$ $\mu \mathrm{l}$ were injected by choice of suitable sampling loops for the injection port. The volume of injected sample was determined as follows. The sampling loop was filled with a standard solution of copper, the contents of the loop were eluted with water into a calibrated flask, the volume of solution in the calibrated flask was adjusted to the mark and the contents were analysed by FAAS, aspirating the solution continuously. The volume of the standard solution injected was calculated from the copper concentration found. The measurements were repeated five times.

The tunable volume dilution chamber was adapted from a $10 \mathrm{ml}$ polyethylene syringe (Fig. 1). The outlet of the syringe was plugged. The piston consists of the inlet, made from a thin walled glass capillary linked to $0.6 \mathrm{~mm}$ i.d. PTFE tubing. Mixing of the contents of the chamber was ensured because the liquid stream entered through the glass capillary. The inner volume of the cylinder was calibrated by weighing the contents. The piston was fixed mechanically to prevent it from being pushing out by the pressure. The inner volume of the chamber can be adjusted from 0.1 to $10 \mathrm{ml}$ continuously.

\section{Procedure}

A calibration graph for copper was prepared by analysing standard solutions of copper in the concentration range $0.1-20$ $\mu \mathrm{g} \mathrm{ml}^{-1}$ using the proposed flow injection (FI) system. The volume of the dilution chamber was set to the minimum value and the standard solution was purged through the system until the steady-state signal was registered. The flow-rate was set to a constant value (about $5 \mathrm{ml} \mathrm{min}^{-1}$ ) and was periodically checked.

The hypothetical tank volume $V_{N}$ of the nebulizer was obtained from the absorbance-time profile ${ }^{9}$ and the value was $91 \pm 2 \mu \mathrm{l}$ at a flow-rate of $5 \mathrm{ml} \mathrm{\textrm {min } ^ { - 1 }}$

In the continuous dilution measurements, water was flushed through the system as the carrier liquid. The volume of the dilution chamber was set to the desired value, the sampling loop was filled with the sample solution and the zero on the instrument was adjusted. The sample was injected into the carrier stream and the absorbance signal was integrated until the value reached the base line again. The transient signal was integrated without the use of a smoothing procedure. The units of peak area (absorbance $\times$ time) are A s.

\section{Results and Discussion}

Fig. 2 illustrates the theoretical dependencies of the relative values of the concentrations, $c_{0}, c_{\mathrm{M}}$ and $c_{\mathrm{N}}$, and peak area on time after sample injection. The concentrations are expressed relative to the original sample concentration $c_{0}$. The relative peak area was calculated as the ratio $a_{t} / a$. The relative absorbance-time dependence is identical with the $c_{\mathrm{N}}-t$ dependence.

The degree of dilution is expressed as dispersion [equation (3)] which is a function of the volumes $V_{0}, V_{\mathrm{M}}$ and $V_{\mathrm{N}}$. The theoretical dependence of dispersion $D$ on the mixing chamber volume for various volumes of the injected sample is depicted in Fig. 3, considering a typical concentric pneumatic nebulizer with a hypothetical tank volume of $0.1 \mathrm{ml}$. A degree of dilution of about ten can be achieved without any mixing chamber, by utilizing the dispersion caused by the nebulizer alone. However, the injected sample volume, should not be larger than about $10 \mu \mathrm{l}$.

To obtain higher degrees of dilution a mixing chamber should be used. The volume of the chamber should be related to the volume of sample injected. By using mixing chambers with volumes of about $10 \mathrm{ml}$, degrees of dilution of more than 


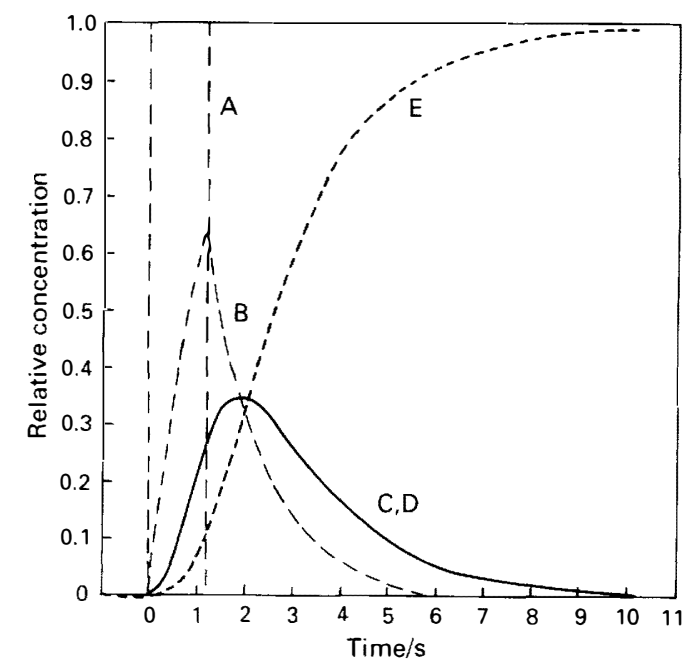

Fig. 2 Time dependence of the relative concentration on $\mathrm{A}, c_{0} ; \mathrm{B}, c_{\mathrm{M}} ; \mathrm{C}$, $c_{N}: D$, absorbance; and $\mathrm{E}$, peak area. Injected sample volume $V_{0}=0.1 \mathrm{ml}$, mixing chamber volume $V_{M}=0.101 \mathrm{ml}$, hypothetical tank volume $V_{\mathrm{N}}=$ $0.1 \mathrm{ml}$ and flow-rate $u=5 \mathrm{ml} \mathrm{\textrm {min } ^ { - 1 }}$

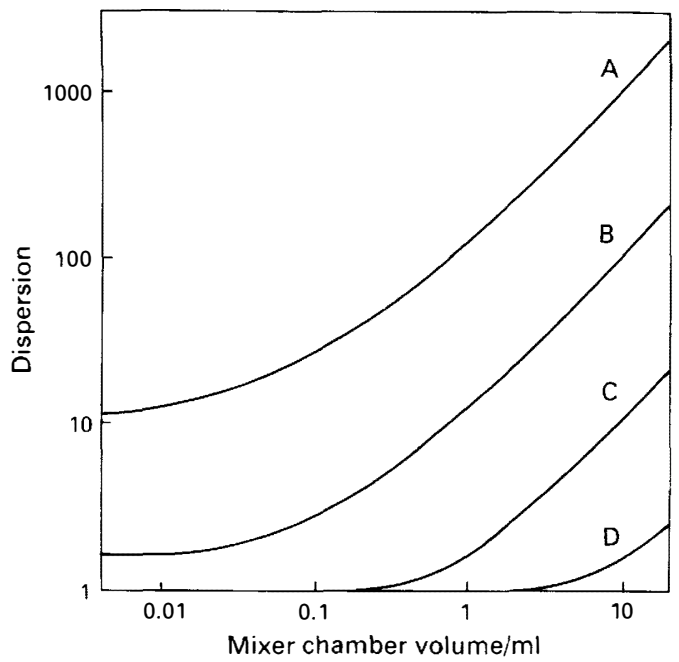

Fig. 3 Dependence of the dispersion $D$ on the mixing chamber volume for injected sample volumes of: A, 0.01; B, 0.1; C, 1: and D, $10 \mathrm{ml}$. Hypothetical tank volume $V_{\mathrm{N}}=0.1 \mathrm{ml}$ and flow-rate $u=5 \mathrm{ml} \mathrm{min}^{-1}$

1000 can be obtained by injecting sample volumes of about $10 \mu \mathrm{l}$.

An important practical point of the use of continuous dilution is the duration of the peak area measurement. Fig. 4 illustrates the time dependences of the relative peak area, $a_{\mathrm{r}}$, $\left(a_{\mathrm{r}}=a_{\mathrm{t}} / a\right)$ for various mixing chamber volumes and $100 \mu \mathrm{l}$ sample volume injections. The measurement time for mixing chambers of volumes up to $1 \mathrm{ml}$ is about $1 \mathrm{~min}$, and that for a $10 \mathrm{ml}$ dilution chamber takes about $10 \mathrm{~min}$. Thus, the duration of the measurement cycle depends considerably on the volumes of the mixing chamber chosen and the sample volume injected.

The volumes of the dilution chamber and sample should be chosen according to the following criteria: (i) the required degree of dilution (dispersion $D$ ) with regard to the analyte concentration; and (ii) the duration of the signal integration.

The possible influence of the parameters $c_{0}, V_{0}$ and $V_{\mathrm{M}}$ on peak area and the validity of equation (4) was investigated. The sample concentration and volume and the dilution chamber volume were varied in a virtually orthogonal design.

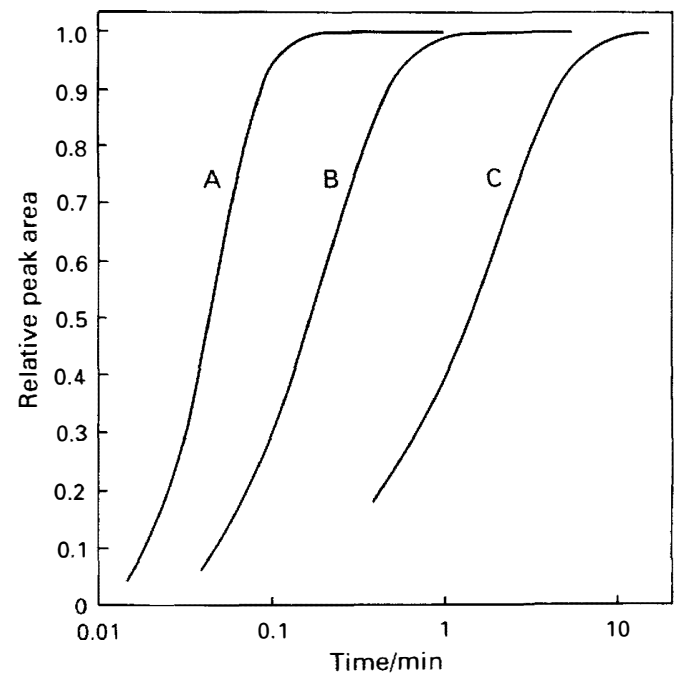

Fig. 4 Dependence of the relative peak area on the integration time for a nebulizer with a hypothetical tank volume $V_{N}=0.1 \mathrm{ml}$. Injected sample volume $V_{0}=0.1 \mathrm{ml}$ and mixing chamber volume $V_{\mathrm{M}}$ : A, $0.1 ; \mathrm{B}, 1$; and $\mathrm{C}$, $10 \mathrm{ml}$. Flow-rate $u=5 \mathrm{ml} \mathrm{\operatorname {min } ^ { - 1 }}$

The simplified Box-Wilson experimental design ${ }^{12}$ was chosen, which demands at least 11 trials if the third order interactions are to be neglected. The values of the parameters used in the trials and the results are collected in Table 1. The flow-rate and the sensitivity were kept constant and were checked after every trial.

The responses (peak areas) obtained for the trials were fitted by the following response surface equation:

$$
\begin{aligned}
a=b_{0} & +b_{1} V_{\mathrm{M}}+b_{2} V_{0}+b_{3} c_{0}+b_{11} V_{\mathrm{M}}^{2}+b_{12} V_{\mathrm{M}} V_{0}+ \\
& +b_{13} V_{\mathrm{M}} c_{0}+b_{22} V_{0}^{2}+b_{23} V_{0} c_{0}+b_{33} c_{0}^{2}
\end{aligned}
$$

where the regression coefficients $b_{i}$ can be calculated by the least-squares method.

The suitability of the fit of the the experimental data was tested with the $F$-test. It was found that all the regression coefficients except for $b_{23}$ were statistically insignificant. Thus, peak area is really only a function of the product $c_{0} V_{0}$. The value of the coefficient $b_{23}$ was calculated again while neglecting the other coefficients. The value was $b_{23}=(0.75 \pm 0.01)$ $\mu \mathrm{g}^{-1} \mathrm{~s}$. Thus, the resulting quadratic equation (6) is the same as equation (4), i.e., the coefficient $b_{23}$ gives the ratio of $k / u$. Since a flow-rate of $u=(6.50 \pm 0.12) \mathrm{ml} \mathrm{min}^{-1}$ was used in these experiments, the sensitivity was $k=(0.080 \pm 0.002)$

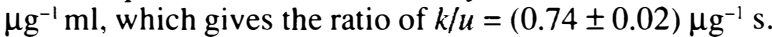

The dynamic range was considered to be the concentration range of copper where the analytical signals (peak area) obtained fit equation (4). The lower limit is given by the minimum peak area that is statistically distinguishable from the blank value (about $0.1 \mathrm{~A} \mathrm{~s}$ ) using the maximum volume of the sample being taken for analysis $(1 \mathrm{ml})$. For copper, a value of about $0.11 \mu \mathrm{g} \mathrm{ml}^{-1}$ was obtained. This detection limit is close to that obtained using continuous aspiration FAAS without a dilution chamber.

The highest analyte concentration in the linear range is governed by the highest dilution chamber volume $(10 \mathrm{ml})$ used, the lowest sample volume being injected $(0.015 \mathrm{ml})$ and by the maximum absorbance in the linear response range using the given experimental parameters [see equation (2)]. At a concentration sensitivity of $k=0.076 \mu \mathrm{g}^{-1} \mathrm{ml}$ for copper and maximum absorbance $A_{\max }=1.0$ in the linear response range, the maximum concentration obtained for copper was about $9160 \mu \mathrm{g} \mathrm{ml}^{-1}$. Thus, the usable concentration range for copper is about five orders of magnitude. For comparison, the linear calibration range without the dilution manifold extends from 
Table 1 Factorial experimental design according to Box and Wilson*

\begin{tabular}{|c|c|c|c|c|c|c|c|c|c|c|c|}
\hline \multirow{2}{*}{ Factor } & \multicolumn{11}{|c|}{ Trial } \\
\hline & 1 & 2 & 3 & 4 & 5 & 6 & 7 & 8 & 9 & 10 & 11 \\
\hline$V_{\mathrm{M}} / \mathrm{ml}$ & 10 & 4 & 4 & 10 & 7 & 10 & 4 & 7 & 7 & 7 & 7 \\
\hline$V_{0} / \mu l$ & 40 & 500 & 40 & 500 & 250 & 250 & 250 & 500 & 15 & 250 & 250 \\
\hline$c_{0} / \mu \mathrm{g} \mathrm{ml}^{-1}$ & 20 & 20 & 140 & 140 & 80 & 80 & 80 & 80 & 80 & 140 & 10 \\
\hline Peak area/A s & 0.57 & 6.56 & 4.29 & 54.0 & 14.6 & 14.2 & 14.1 & 28.0 & 0.81 & 26.3 & 1.53 \\
\hline Standard deviation/A s & 0.03 & 0.04 & 0.23 & 0.7 & 0.3 & 0.3 & 0.1 & 0.4 & 0.13 & 0.1 & 0.07 \\
\hline
\end{tabular}

* See reference 12 .

Table 2 Analyses of synthetic samples

\begin{tabular}{ccccc}
$\begin{array}{c}\text { Copper } \\
\begin{array}{c}\text { concentration/ } \\
\mu \mathrm{g} \mathrm{m}^{-1}\end{array}\end{array}$ & $\begin{array}{c}\text { Sample } \\
\text { volume/ } \\
\mathrm{ml}\end{array}$ & $\begin{array}{c}\text { Dilution } \\
\text { chamber volume/ } \\
\mathrm{ml}\end{array}$ & \multicolumn{2}{c}{$a / V_{0} / \mathrm{s} \mathrm{ml}^{-1}$} \\
\cline { 3 - 5 } 0.1 & 0.760 & 0.2 & $<0.13$ & 0.09 \\
0.2 & 0.760 & 0.2 & $0.20 \pm 0.03$ & 0.182 \\
1.0 & 0.760 & 0.2 & $0.93 \pm 0.03$ & 0.912 \\
10 & 0.238 & 1 & $9.0 \pm 0.2$ & 9.12 \\
100 & 0.120 & 1 & $90.8 \pm 2.5$ & 91.2 \\
& 0.238 & 4 & $94.1 \pm 1.7$ & - \\
300 & 0.760 & 10 & $92.1 \pm 2.6$ & - \\
1000 & 0.120 & 5 & $268 \pm 8$ & 274 \\
& 0.015 & 2 & $920 \pm 20$ & 912 \\
& 0.015 & 4 & $907 \pm 20$ & - \\
3000 & 0.015 & 6 & $927 \pm 27$ & - \\
9000 & 0.015 & 8 & $880 \pm 53$ & - \\
10000 & 0.015 & 10 & $2830 \pm 130$ & 2740 \\
& 0.015 & 10 & $8330 \pm 350$ & 8210 \\
& & 10 & $8670 \pm 330$ & 9120
\end{tabular}

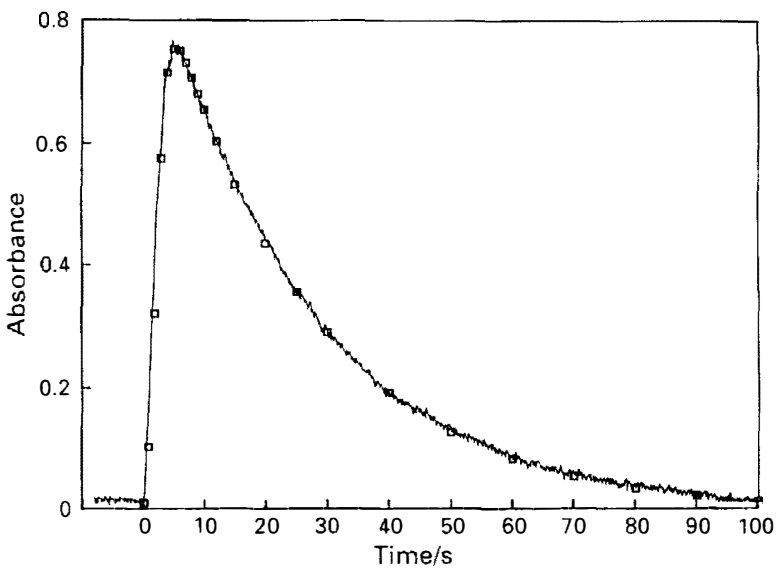

* Confidence interval ( $95 \%$ ) calculated from five measurements

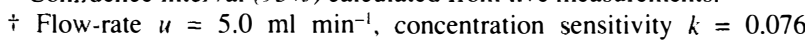
$\mu \mathrm{g}^{-1} \mathrm{ml}$.

about 0.1 to $10-15 \mu \mathrm{g} \mathrm{ml}^{-1}$, i.e., 2-3 orders of magnitude. Achieving large dispersions for highly concentrated samples is, however, handicapped by the prolonged measurement times required, up to $10 \mathrm{~min}$.

The signals measured for synthetic copper samples at various concentrations are given in Table 2 . The experimental data correspond well with the calculated values in the concentration range from 0.2 to $9000 \mu \mathrm{g} \mathrm{ml}^{-1}$, which confirms the theoretical conclusions detailed in this paper. In this range, the ratio $a / V$, for a given analyte concentration is independent of the sample volume injected and of the dilution chamber volume, respectively. The last two parameters, however, have to ensure appropriate dispersion of the system [equation (3)] in order for the signal to lie within the linear response range.

The peak area values were obtained either by integrating the absorbance values or by using transmittance values according to equation (5). No significant difference was observed between the two sets of results.

Fig. 5 shows a typical chart recording of the transient signal. After having taken the experimental parameters $\left(u, k, V_{\mathrm{M}}, V_{\mathrm{N}}\right.$, $c_{0}$ and $V_{0}$ ) into account, the absorbance-time dependence was calculated. The calculated values evidently fit the experimental dependence, implying that the experimental system can be described by a model consisting of two tanks in series. Similar agreement was observed for mixing chamber volumes of from 1 to $8 \mathrm{ml}$. At flow-rates lower than $5 \mathrm{ml} \mathrm{min}^{-1}$ the fit deteriorated, probably owing to insufficient mixing of the contents of the dilution chamber, as the liquid entering the chamber is at a lower velocity. The peak areas in these instances, however, corresponded to equation (4). From the practical point of view,

Fig. 5 Chart recording of the absorbance-time dependence for the analysis of $238 \mu \mathrm{l}$ of a copper solution $\left(100 \mu \mathrm{g} \mathrm{ml}^{-1}\right)$ using a dilution chamber of volume $2.05 \mathrm{ml}$. Flow-rate $u=5 \mathrm{ml} \mathrm{min}^{-1}$, sensitivity $k=0.076 \mu \mathrm{g}^{-1}$ $\mathrm{ml}$, hypothetical tank volume for the nebulizer $V_{\mathrm{N}}=0.09 \mathrm{ml}$. Calculated values are given by the square symbols

peak area measurement is much less sensitive to deviations from the ideal behaviour of the system compared with time based methods. ${ }^{1.46 .7}$

The method was used for the determination of magnesium in a mineral water (Salvator, Czechoslovakia). To suppress the formation of magnesium oxide in the flame, $0.1 \mathrm{~mol} \mathrm{dm}^{-3} \mathrm{HCl}$ was used as the carrier liquid. The experimental parameters were as follows: dilution chamber volume, $6 \mathrm{ml}$; and sample volume injected, $15 \mu \mathrm{l}$. The proposed method gave a value of $169 \pm 4 \mu \mathrm{g} \mathrm{ml}^{-1}$. The magnesium content was also determined by the calibration graph method after off-line dilution of the sample with $0.1 \mathrm{~mol} \mathrm{dm}^{-1} \mathrm{HCl}$ in a calibrated flask. The magnesium concentration found by this method was $171 \pm 3$ $\mu \mathrm{g} \mathrm{ml} l^{-1}$.

\section{Conclusions}

The proposed method facilitates enhancement of the linear calibration range of FAAS by 2-3 orders of magnitude while keeping the instrumental parameters at the same, preferably optimum, values. The calibration procedure is simple and universal for the whole concentration range. Moreover, as with other FI arrangements, the method is amenable to automation. The disadvantage of the method arises from the long duration of the measurements for high concentration samples.

Since peak area is measured, the mixing efficiency in the mixing chamber does not play such an important role as it does when absorbance measurements are used as in timebased methods. 


\section{References}

1 Tyson, J. F., and Appleton, J. M. H., Talanta, 1984, 31, 9.

2 Tyson, J. F., Mariara, J. R., and Appleton, J. M. H., J. Anal. At. Spectrom., 1986, 1, 273.

3 Tyson, J. F., and Bysouth, S. R., J. Anal. At. Spectrom., 1988, 3, 211.

4 de la Guardia, M., Carbonell, V., Morales A., and Salvador, A., Fresenius Z. Anal. Chem.. 1989, 335, 975.

5 Reis, B. F., Jacintho, A. O., Mortatti, J., Krug, F. J., Zagatto, E. A. G., Bergamin, H. F., and Pessenda, L. C. R., Anal. Chim. Acta, 1981, $123,221$.

6 Tyson, J. F., Analyst, 1984, 109, 319.

7 Bysouth, S. R., and Tyson, J. F., Anal. Chim. Acta, 1986, 179, 481.
8 Tyson, J. F., Appleton, J. M. H., and Idris, A. B., Anal. Chim. Acta, $1983,145,159$

9 Appleton, J. M. H., and Tyson. J. F., J. Anal. At. Spectrom., 1986, 1, 63.

10 Stone, D. C., and Tyson, J. F., Analyst, 1989, 114, 1453.

11 Tyson, J. F., Anal. Chim. Acta, 1988, 214, 57.

12 Davies, O. L., Design and Analysis of Industrial Experiments, Oliver and Boyd, Edinburgh, 1956.

Paper 0105019l

Received November 7th, 1990

Accepted January 14th, 1991 